\title{
UJI PERBANDINGAN MOTIVASI BELAJAR SISWA KELAS XI MIPA 2 DAN XII MIPA 2 DI SMA NEGERI 1 MUARO JAMBI
}

\author{
*Maria Marisa Matondang \\ Universitas Jambi \\ marisamaria172@gmail.com
}

Endah Febri Setiya Rini

Universitas Jambi

endahfebri9@gmail.com

Novita Dwi Putri

Universitas Jambi

novitadwiputri14@gmail.com

Fauziah Yolviansyah

Universitas Jambi

fauziahyolviansyah1@gmail.com
Abstrak - Penelitian ini bertujuan untuk melihat perbandingan motivasi belajar siswa kelas XI dan kelas XII. Penelitian ini menggunakan metode penelitian kuantitatif deskriptif dengan menggunakan instrumen berupa angket motivasi belajar siswa. Sampel penelitian ini yaitu siswa kelas XI MIPA 2 dan kelas XII MIPA 2 di SMA NEGERI 1 MUARO JAMBI tahun ajaran 2020/2021 yang berjumlah 60 responden. Teknik analisis data yang digunakan peneliti yaitu menggunakan software IBM SPSS 23, dengan melakukan Uji Normalitas, Uji Homogenitas, dan Uji Perbandingan. Data yang didapatkan peneliti telah terdistribusi normal dan homogen, sehingga peneliti dapat menggunakan uji perbandingan. Adapun hasil uji perbandingan ini yaitu nilai signifikan pengujian dua arah Sig.(2-tailed) sebesar 0,207 pada Equal variance not assumed, dan nilai signifikan pengujian dua arah Sig.(2-tailed) untuk Equal variance assumed dan nilai untuk Equal variance not assumed sebesar 0,208. Hasil penelitian menunjukkan tidak terdapat perbedaan yang signifikan pada hasil motivasi belajar siswa antara siswa kelas XI MIPA 2 dan XII MIPA 2.

Kata Kunci : Motivasi Belajar Siswa, Fisika, Uji Perbandingan.

Abstract - This study aims to compare the learning motivation of class XI and class XII students. This study uses descriptive quantitative research methods using instruments in the form of a student learning motivation questionnaire. The samples of this research were students of class XI MIPA 2 and class XII MIPA 2 at SMA NEGERI 1 MUARO JAMBI in the academic year 2020/2021, totaling 60 respondents. The data analysis technique used by researchers is using SPSS IBM 23 software, by performing a Normality Test, Homogeneity Test, and Comparative Test. The data obtained by researchers has been normally distributed and homogeneous, so that researchers can use a comparison test. The results of this comparison test are the significant value of the twoway Sig. (2-tailed) of 0.207 on Equal variance not assumed, and the significant value of the two-way Sig. (2-tailed) test for Equal variance assumed and the value for Equal variance not assumed. amounting to 0.208. The results showed that there was no significant difference in the results of student motivation between class XI MIPA 2 and XII MIPA 2.

Keywords: Student Learning Motivation, Physics, Comparative Test. 


\section{A. PENDAHULUAN}

Kita sebagai orang yang hidup di era milenial tidak lepas dengan yang namanya teknologi. Ada saja pembaharuan teknologi di setiap keseharian kita. Tanpa adanya teknologi,aktifitas yang kita jalain setiap hari pasti akan mengalami hambatan.Teknologi juga tidak lepas kaitanya dengan fisika dan pendidikan. Pendidikan sendiri menurut Oktaviana (2016) adalah cara mempengaruhi peserta didik untuk mampu menempatkan diri terhadap lingkunganya, agar dapat menumbuhkan perubahan yang lebih baik lagi didalam dirinya. Namun, Menurut Suharyanto (2015), pendidikan merupakan proses manusia supaya dapat menunjukkan perilakunya sebagai makhluk sosial yang mampu berbudaya dalam masyarakat luas dan juga dapat menempatkan diri dalam lingkungannya dengan upaya mempertahankan diri.

Pendidikan yang ada di Indonesia dilaksanakan melaui jalur, jenjang dan jenis pendidikan. Jalur pendidikan adalah proses yang dilalui peserta didik untuk dapat menumbuhkan potensi diri dalam suatu kiat pendidikan yang sesuai dengan tujuan pendidikan. Ada tiga jalur pendidikan antara lain, jalur pendidikan formal, nonformal dan informal. Pendidikan formal adalah pendidikan yang tersusun dan bertahap yang terbagi atas pendidikan dasar, pendidikan menengah pertama dan pendidikan menengah atas. Pendidikan nonformal adalah pendidikan yang diadakan diluar pendidikan formal yang tersusun dan bertahap. Dan pendidikan informal adalah pendidikan yang berasal dari keluarga dan lingkungan (Raharjo, 2012).

Pendidikan menengah atas di Indonesia terbagi menjadi 2 fokus program yaitu ilmu alam dan ilmu sosial. Salah satu mata pelajaran pada ilmu alam yaitu fisika. Menurut Setia (2017), fisika adalah ilmu IPA yang mempelajari tentang alam dan interaksinya disertai fenomena yang mengkutinya. Menurut pendapat secara umum, banyak siswa yang berpendapat bahwa mata pelajaran fisika sangat sulit dan mengandung banyak rumus yang akhirnya sulit dimengerti oleh siswa saat diajarkan guru.

Sebagai mana yang kita ketahui, bahwa pelajaran fisika itu merupakan pelajaran yang cukup sulit dimengerti siswa karena terdapat banyak rumus dan konsep-konsep. Sehingga, kebanyakan siswa beranggapan mata pelajaran fisika itu sangat membosankan dan sulit. Hal ini juga dikarenakan guru yang mengajar kurang kreatif dan inovatif sehingga pembelajaran kurang bermakna. Masih banyak guru-guru yang menggunakan metode konvensional salah satunya metode ceramah. Sebenarnya, siswa yang menjadi pusat saat pembelajaran berlangsung. Siswa dituntut berperan aktif agar kegiatan dan tujuan pembelajaran dapat diserap secara optimal. Disamping itu, guru bisa dikatakan berhasil dalam memberikan ilmu, saat dalam kegiatan pembelajaran berlangsung guru tidak hanya menyampaikan, tetapi juga menyampaikan informasi mulai dari peristiwa-peristiwa yang ada di sekitar lingkungan siswa berada. Peristiwa ini dapat memicu peningkatan motivasi belajar siswa.

Menurut Hamdu \& Agustina (2011), berhasil tidaknya tujuan pengajaran salah satunya adalah tampak dari hasil belajar yang digapai siswa. Pada prestasi yang tinggi, siswa memiliki bakat berpengetahuan yang baik. Motivasi merupakan salah satu faktor yang mempengaruhi prestasi pada 
siswa. Karena adanya motivasi, siswa mau belajar lebih bersemangat, giat, dan tekun. Juga memiliki konsentrasi penuh, dalam proses pembelajaran.

Menurut Wasty Soemanto dalam Hamdu (2011) pengenalan seseorang terhadap prestasi belajarnya adalah penting, karena dengan mengetahui hasil-hasil yang sudah dicapai maka siswa akan lebih berusaha meningkatkan prestasi belajarnya. Dengan demikian peningkatan prestasi belajar dapat lebih optimal karena siswa tersebut merasa termotivasi untuk meningkatkan prestasi belajar yang telah diraih sebelumnya mutu prestasi belajar pada siswa perlu diperkuat terus-menerus. Dengan tujuan agar siswa memiliki motivasi belajar yang kuat, sehingga prestasi belajar yang diraihnya dapat optimal.

Menurut Handoko dalam Suprihatin (2015), untuk memahami kekuatan motivasi belajar siswa, dapat diamati dari beberapa indikator sebagai berikut :

1) Kuatnya kemauan untuk berbuat

2) Jumlah waktu yang disediakan untuk belajar

3) Kerelaan meninggalkan kewajiban atau tugas yang lain

4) Ketekunan dalam mengerjakan tugas.

Menurut Sardiman dalam Basuki (2015), motivasi belajar memiliki ciri-ciri, yaitu:

1) Tekun menghadapi tugas

2) Tidak lekas putus asa

3) Menunjukkan minat terhadap bermacam- macam masalah untuk orang dewasa

4) Bekerja mandiri.

5) Cepat bosan pada tugas- tugas rutin

6) Teguh dalam pendirian

7) Tidak mudah melepaskan hal yang diyakininya itu.

8) Senang mencari dan memecahkan masalah soal-soal.

Menurut beberapa pendapat yang dikemukakan di atas, motivasi adalah dorongan yang dapat menimbulkan keinginan dalam melakukan suatu kegiatan. Keinginan baik yang berasal dari dalam diri sendiri (motivasi intrinsik) maupun dari luar diri sendiri (motivasi ekstrinsik). Besarnya dorongan motivasi yang dimiliki seseorang akan menentukan kualitas kepribadian yang tercermin, baik dalam ranah pembelajaran, pekerjaan ataupun dalam kehidupan lainnya.

Berdasarkan latar belakang diatas, penelitian ini bertujuan untuk mengetahui perbandingan motivasi belajar fisika pada siswa XI dan XII, apakah terdapat perbedaan antara kedua kelas tersebut dengna cara uji perbandingan.

\section{B. METODE}

Penelitian ini dilakukan di SMA Negeri 1 Muaro Jambi pada 20-23 Oktober 2020. Waktu penelitan dilaksanakan pada semester ganjil tahun ajaran 2020/2021. Data sampel penelitian yaitu 
siswa kelas XI MIPA 2 dan XII MIPA 2 dengan jumlah responden 30 orang perkelas. Penelitian ini menggunakan metode penelitian kuantitatif deskriptif. Metodologi penelitian kuantitatif deskriptif adalah penelitian yang menguraikan suatu materi yang diteliti melalui data atau sampel dalam kondisi yang terstruktur, teratur dan sistematik.

Sampel merupakan perwakilan data yang di ambil untuk di teliti dan diduga sudah mewakilkan keseluruhan objek (Mulia \& Saputra, 2020). Teknik sampling yang digunakan adalah total sampling. Total responden pada penelitian ini berjumlah 60 orang siswa yang berasal dari kelas XI MIPA 2 dan XII MIPA 2 dari SMA N 1 Muaro Jambi. Waktu penyebaran angket dilakukan pada 20-23 Oktober 2020. Penelitian ini memakai teknik analisis perbandingan atau uji T.

Penelitian ini menggunakan Quesioner. Quesioner ini menggunakan 4 skala (skala likert). Quesioner yang digunakan dalam penelitian ini terdiri dari 39 butir soal. Quesioner ini digunakan untuk mengetahui sejauh mana motivasi belajar siswa dalam pelajaran fisika. Quesioner disebarkan ke dua kelas yang berbeda tingkatanya. Selanjutnya, data yang didapat diolah dan dianalisis menggunakan software pengolahan data SPSS.

Analisis data pada penelitian ini menggunakan analisis perbandingan atau uji $\mathrm{T}$ dengan menggunakan menggunakan software pengolahan data SPSS guna mencari data perbandingan antar kedua kelas. Tujuan dari analisis perbandingan ini adalah untuk membuktikan apakah motivasi belajar siswa yang satu dengan kelas yang lain memiliki perbedaan atau tidak dalam pembelajaran fisika yang ada di sekolah SMA N 1 Muaro Jambi.

\section{HASIL DAN PEMBAHASAN}

\section{Hasil}

Penelitian ini bertujuan untuk mengetahui motivasi siswa pada pelajaran fisika. Penelitian ini juga membantu guru SMA Negeri 1 Muaro Jambi untuk mengetahui bagaimana perbandingan motivasi belajar siswa di kelas XI MIPA 2 Dan XII MIPA 2 pada pelajaran fisika. Motivasi belajar siswa juga dapat mengetahui bagaimana sikap siswa terhadap mata pelajaran Fisika dan juga mengetahui tingkat prestasi siswa di bidang fisika. Hasil analisis statistik deskriptif didapat dengan menggunakan software pengolahan data SPSS mengenai motivasi belajar siswa pada pelajaran fisika terhadap siswa kelas XI MIPA 2 dan XII MIPA 2 di SMA Negeri 1 Muaro Jambi. Pada hasil yang didapat ini terdapat beberapa uji yang dilakukan untuk membuktikan apakah diantara kelas memiliki perbandingan atau tida. Adapun uji yang dilakukan antara lain: uji normalitas, uji homogenitas dan uji perbandingan (uji T). 


\section{Uji Normalitas}

Tabel 1. Uji Normalitas Motivasi Belajar Siswa Kelas XI MIPA 2 SMAN 1 Muaro Jambi.

\begin{tabular}{cc}
\hline Kolmogorov-Smirnov & Hasil \\
\hline Statistic & 0,132 \\
df & 30 \\
Sig. & 0,190 \\
\hline Shapiro-Wilk & Hasil \\
\hline Statistic & 0,966 \\
df & 30 \\
Sig. & 0.443 \\
\hline
\end{tabular}

Berdasarkan tabel 1. Statistik Uji Normalitas motivasi belajar siswa kelas XI MIPA 2 SMAN 1 Muaro Jambi memperoleh data bahwa data Kolmogorov-Smirnov menunjukkan nilai statistik sebesar 0,132, degree of freedom (df) atau derajat sebesar 30 dan signifikan sebesar 0,190. Sedangkan data Shapiro-Wilk menunjukkan nilai statistik sebesar 0,966, degree of freedom (df) atau derajat sebesar 30 dan signifikan sebesar 0,443. Dalam penelitian ini kelas XI MIPA 2 SMAN 1 Muaro Jambi sebanyak 30 siswa sehingga data yang diambil adalah data Kolmogorov-Smirnov.

Tabel 2. Uji Normalitas Hasil Motivasi Belajar Siswa Kelas XII MIPA 2 SMAN 1 Muaro Jambi.

\begin{tabular}{cc}
\hline Kolmogorov-Smirnov & Hasil \\
\hline Statistic & 0,112 \\
df & 30 \\
Sig. & 0,200 \\
\hline Shapiro-Wilk & Hasil \\
\hline Statistic & 0,942 \\
df & 30 \\
Sig. & 0.101 \\
\hline
\end{tabular}

Berdasarkan tabel 2. Statistik Uji Normalitas motivasi belajar siswa kelas XII MIPA 2 SMAN 1 Muaro Jambi memperoleh data bahwa data Kolmogorov-Smirnov menunjukkan nilai statistik sebesar 0,112, degree of freedom (df) atau derajat sebesar 30 dan signifikan sebesar 0,200. Sesdangkan data Shapiro-Wilk menunjukkan nilai statistik sebesar 0,942 , degree of freedom (df) atau derajat sebesar 30 dan signifikan sebesar 0,101. Dalam penelitian ini kelas XI MIPA 2 SMAN 1 Muaro Jambi sebanyak 30 siswa sehingga data yang diambil adalah data Kolmogorov-Smirnov. 


\section{Uji Homgenitas}

Tabel 3. Statistik Uji Homogenitas Hasil Motivasi Belajar Siswa Kelas XI MIPA 2 dan XII MIPA 2 SMAN 1 Muaro Jambi.

\begin{tabular}{cc}
\hline & Hasil \\
\hline Levene Statistic & 1,748 \\
\hline df1 & 1 \\
df2 & 58 \\
Sig & 0,191 \\
\hline
\end{tabular}

Berdasarkan tabel 3. Statistik Uji Homogenitas motivasi belajar siswa kelas XI MIPA 2 dan XII MIPA 2 di SMAN 1 Muaro Jambi memperoleh data bahwa data nilai Levene Statistic sebesar 1,748 , degree of freedom ( $\mathrm{df1}$ ) atau derajat sebesar 1, degree of freedom (df2) atau derajat sebesar 58 , dan signifikan sebesar 0,191 .

\section{Uji Perbandingan}

Tabel 4. Statistik Uji Perbandingan (Uji -T) Hasil Motivasi Belajar Siswa Kelas XI MIPA 2 dan XII MIPA 2 SMAN 1 Muaro Jambi.

\begin{tabular}{ccl}
\hline $\begin{array}{c}\text { Levene's Test for } \\
\text { Equality of Variance }\end{array}$ & $\begin{array}{c}\text { Equal } \\
\text { variance } \\
\text { assumed }\end{array}$ & $\begin{array}{l}\text { Equal } \\
\text { variance not } \\
\text { assumed }\end{array}$ \\
\hline $\boldsymbol{F}$ & 1,748 & \\
\hline Sig. & 0,191 & \\
\hline t-test for Equality of & & \\
Means & & $-1,276$ \\
\hline $\boldsymbol{t}$ & $-1,276$ & 51,898 \\
$\boldsymbol{d} \boldsymbol{S}$ & 58 & 0,208 \\
\hline Sig.(2-tailed) & 0,207 & \\
\hline
\end{tabular}

Berdasarkan tabel 4. Statistik Uji Perbandingan (Uji -T) motivasi belajar siswa kelas XI MIPA 2 dan XII MIPA 2 di SMAN 1 Muaro Jambi memperoleh data bahwa data pada Levene's Test for Equality of Variance nilai frekuensi (F) Equal variance assumed sebesar 1,748, signifikan Equal variance assumed sebesar 0,191, dan pada data t-test for Equality of Means nilai uji parsial atau uji $-\mathrm{t}$ sebesar -1,276 untuk Equal variance assumed dan Equal variance not assumed, nilai degree of freedom (df) atau derajat sebesar 58 untuk Equal variance not assumed dan nilai degree of freedom (df) atau derajat sebesar 51,898 untuk Equal variance not assumed, dan nilai signifikan pengujian dua arah Sig.(2-tailed) untuk Equal variance assumed sebesar 0,207 dan nilai untuk Equal variance not assumed sebesar 0,208.

\section{Pembahasan}

Proses pembelajaran adalah suatu proses kegiatan menyampaikan ilmu antara guru ke siswa. Pada proses ini pembelajaran pada mata pelajaran fisika, semestinya selalu mengikutsertakan siswa 
agar aktif untuk mengembangkan kemampuannya. Karena itu, diperlukan kemampuan untuk berfikir secara logis, kreatif dan kritis agar tercapainya tujuan pembelajaran (Purwanto, 2016). Pada umumnya pembelajaran adalah proses perubahan yang berarti perubahan dalam bentuk perilaku dan sikap sebagai hasil interaksi antara dirinya dengan lingkungan untuk memenuhi kebutuhan hidupnya (Lestari, 2017).

\section{Uji Normalitas}

Uji normalitas adalah bagian dari ilmu statistika yang digunakan untuk menguji apakah data yang digunakan mempunyai distribusi normal atau tidak agar dapat dipakai dalam statistik parametrik. Dengan artian, uji normalitas adalah uji yang digunakan untuk mengetahui apakah data yang didapatkan sesuai dengan distribusi teoritis tertentu (Kabasarang, 2013). Pada pengujian normalitas yang dilakukan dengan software program SPSS Statistic 23. Berdasarkan tingkat keakuratan 95\% syarat suatu data dapat dikatakan "normal" apabila sig $>0,05$ maka data dapat dikatakan "normal", tetapi jika data yang didapat nilainya sig $<0,05$ maka data dikatakan "tidak normal". Menurut (Raningsih, 2015), tujuan dari uji normalitas adalah untuk menguji apakah data yang digunakan normal atau tidak, dilakukan menggunakan uji Kolmogorov Sminarnov ataupun Shapiro-Wilk. uji Kolmogorov Sminarnov digunakan untuk data yang lebih banyak dari 30 sampel sedangkan uji Shapiro-Wilk untuk data yang lebih sedikit dari 30 sampel.

Berdasarkan hasil data yang ada di atas dapat di ambil kesimpulan bahwa motivasi belajar siswa pada pelajaran fisika kelas XI MIPA 2 memiliki nilai signifikasi sebesar 0,190, nilai statistic sebesar 0,132 dan nilai df sebesar 30 yang dapat kita lihat pada data Kolmogorov Sminarnov, sehingga dapat disimpulkan bahwa motivasi belajar fisika di kelas kelas XI MIPA 2 teruji normal. Sementara untuk kelas kelas XII MIPA 2 memiliki nilai signifikasi sebesar 0,200, nilai statistik sebesar 0,112 dan nilai df sebesar 30 yang dapat kita lihat pada data Kolmogorov Sminarnov, sehingga dapat disimpulkan bahwa motivasi belajar fisika di kelas XII MIPA 2 teruji normal. Berdasarkan tingkat keakuratan 95\% syarat suatu data dapat dikatakan "normal" apabila sig $>0,05$ maka data dapat dikatakan "normal", tetapi jika data yang didapat nilainya sig $<0,05$ maka data dikatakan "tidak normal". Maka, motivasi belajar siswa pada pelajaran fisika pada kelas XI MIPA 2 dan XII MIPA 2 dikategorikan "Normal".

\section{Uji Homogenitas}

Menurut Matondang (2009), uji homogenitas adalah memberikan keyakinan bahwa sekumpulan data yang dimanipulasi dalam serangkaian analisis yang berasal dari populasi namun tidak jauh berbeda keragamannya. Selain penguji normalitas pada data, diperlukan juga diuji homogenitas. Uji homogenitas merupakan pengujian untuk mengetahui sama tidaknya variansivariansi dua buah distribusi atau lebih (Jonnadi, 2012). 
Berdasarkan hasil data di atas dengan menggabungkan kedua sampel kelas, di peroleh nilai signifikan sebesar 0,191, nilai levene statistic sebesar 1,748, nilai degree of freedom (df1) atau derajat sebesar 1, nilai degree of freedom (df2) atau derajat sebesar 58. Dalam uji homogenitas yang dilakukan dengan software program pengolahan data SPSS Statistic 23. Berdasarkan tingkat keakuratan 95\% syarat suatu data dapat dikatakan "homogen" apabila sig > 0,05 maka data dapat dikatakan "homogen", tetapi jika data yang didapat nilainya sig $<0,05$ maka data dikatakan "tidak homogen”. Maka, motivasi belajar siswa pada pelajaran fisika pada kelas XI MIPA 2 dan XII MIPA 2 dikategorikan "Homogen".

\section{Uji Perbandingan}

Uji-T 2 sampel independen (bebas) merupakan metode yang digunakan untuk menguji kesamaan rata-rata dari 2 populasi yang sifatnya independen, yang mana peneliti tidak mempunyai informasi mengenai ragam populasi. Independen merupakan populasi yang satu tidak dipengaruhi atau tidak berhubungan dengan populasi yang lain. Kondisi dimana peneliti tidak memiliki informasi mengenai ragam populasi merupakan kondisi yang paling sering dijumpai di kehidupan nyata. Oleh karena itu pada umum, uji-T (baik 1-sampel, 2-sampel, independen maupun paired) merupakan metode yang paling sering digunakan untuk menguji perbandingan sampel (Kurniawan, 2008).

Uji perbandingan ini dilakukan untuk membandingkan suatu variable A dengan variable B, apakah terdapat perbedaan rata-rata pada dua sampel yang tidak berpasangan. Uji ini dilakukan pada kelas yang berbeda dengan menggunakan data motivasi belajar siswa kelas XI MIPA 2 dan XII MIPA 2. Syarat data parametrik pada uji perbanding data harus normal dan homogen, maka barulah dapat dilakukannya uji independent samples test $(\mathrm{Uji}-\mathrm{T})$. Sedangkan syarat untuk data non-parametrik pada uji perbandingan apabila terdapat salah satu data tidak normal ataupun tidak homogen, maka dapat dilakukan uji Mann-Whitney U.

Berdasarkan hasil data di atas, di peroleh data bahwa data pada Levene's Test for Equality of Variance nilai frekuensi (F) Equal variance assumed sebesar 1,748, signifikan Equal variance assumed sebesar 0,191, dan pada data t-test for Equality of Means nilai uji parsial atau uji - $t$ sebesar 1,276 untuk Equal variance assumed dan Equal variance not assumed, nilai degree of freedom (df) atau derajat sebesar 58 untuk Equal variance not assumed dan nilai degree of freedom (df) atau derajat sebesar 51,898 untuk Equal variance not assumed, dan nilai signifikan pengujian dua arah Sig.(2tailed) untuk Equal variance assumed sebesar 0,207 dan nilai untuk Equal variance not assumed sebesar 0,208. Berdasarkan tingkat keakuratan 95\% syarat suatu data dapat dikatakan " tidak terdapat perbedaan yang signifikan" apabila sig. (2-tailed) > 0,05 maka data dapat dikatakan "tidak terdapat perbedaan yang signifikan" tetapi jika data yang didapat nilainya sig. (2-tailed) $<0,05$ maka data dikatakan "terdapat perbedaan yang signifikan". Maka, motivasi belajar siswa pada pelajaran fisika pada kelas XI MIPA 2 dan XII MIPA 2 dikategorikan “Tidak terdapat perbedaan yang signifikan”. 


\section{SIMPULAN}

Berdasarkan tujuan penelitian, hasil dan pembahasan. Maka penelitian yang dilaksankan di SMA Negeri 1 Muaro Jambi pada kelas XI MIPA 2 dan XII MIPA 2 yaitu untuk mengetahui sejauh mana motivasi belajar fisika yang ada dalam diri siswa. Maka dari itu, dalam penelitian ini bertujuan untuk mengetahui perbandingan motivasi belajar fisika pada siswa XI dan XII, apakah terdapat perbedaan antara kedua kelas tersebut dengna cara uji perbandingan. Maka hasil yang di dapatkan adalah:

1. Motivasi Belajar Siswa Pada Pelajaran Fisika pada kelas XI MIPA 2 dan XII MIPA 2 dikategorikan "Normal" karena mendapatkan nilai signifikan sebesar 0,190 pada kelas XI MIPA 2 dan pada kelas XII MIPA 2 sebesar 0,200.

2. Motivasi Belajar Siswa Pada Pelajaran Fisika pada kelas XI MIPA 2 dan XII MIPA 2 dikategorikan "Homogen" karena mendapatkan nilai signifikan sebesar 0,191.

3. Motivasi Belajar Siswa Pada Pelajaran Fisika pada kelas XI MIPA 2 dan XII MIPA 2 dikategorikan "Tidak terdapat perbedaan yang signifikan" karena mendapatkan nilai signifikan pengujian dua arah Sig.(2-tailed) sebesar 0,207 pada Equal variance not assumed, dan nilai signifikan pengujian dua arah Sig.(2-tailed) untuk Equal variance assumed dan nilai untuk Equal variance not assumed sebesar 0,208.

\section{DAFTAR RUJUKAN}

Basuki, K. H. (2015). Pengaruh kecerdasan spiritual dan motivasi belajar terhadap prestasi belajar matematika. Formatif: Jurnal Ilmiah Pendidikan MIPA, 5(2).

Hamdu, G., \& Agustina, L. (2011). Pengaruh motivasi belajar siswa terhadap prestasi belajar IPA di sekolah dasar. Jurnal penelitian pendidikan, 12(1), 90-96.

Jonnadi, A., Amar, S., \& Aimon, H. (2012). Analisis pertumbuhan ekonomi dan kemiskinan di indonesia. Jurnal Kajian Ekonomi, 1(1).

Kabasarang, D. C., Setiawan, A., \& Susanto, B. (2013). Uji Normalitas Menggunakan Statistik Jarque-Bera Berdasarkan Metode Bootstrap. In Seminar Nasional Pendidikan Matematika.

Kurniawan, D. (2008). Uji t 2-Sampel Independen. Jurnal Statistik.

Lestari, P. (2017). Penerapan Model Pembelajaran Teams Game Tournament (TGT) Berharga Untuk Meningkatkan Aktivitas Dan Hasil Belajar Kalor Siswa Kelas X. Jurnal Profesi Keguruan, 3(2), 135-142.

Matondang, Z., \& Pengantar, A. (2009). Pengujian homogenitas varians data. Medan: Taburasa PPS UNIMED.

Mulia, R. A., \& Saputra, N. (2020). Analisis Faktor-Faktor Yang Mempengaruhi Kesejahteraan Masyarakat Kota Padang. Jurnal EL-RIYASAH, 11(1), 67-83. 
Oktaviana, D. (2016). Penerapan rpp berbasis multiple intelligences untuk meningkatkan aktivitas dan hasil belajar fisika siswa pada materi kalor dan perpindahan kalor kelas x mia 4 sma negeri 3 kota jambi. Edufisika: Jurnal Pendidikan Fisika, 1(1).

Purwanto, A. (2016). Peningkatan Aktivitas dan Hasil Belajar Siswa Pada Mata Pelajaran IPA dengan Menggunakan Metode Examples Non Examples Di Kelas VIIh SMP 5 Kudus Semester II Tahun Pelajaran 2014/2015. Jurnal Profesi Keguruan, 2(1), 36-41.

Raharjo, S. B. (2012). Evaluasi trend kualitas pendidikan di indonesia. Jurnal Penelitian dan Evaluasi Pendidikan, 16(2), 511-532.

Raningsih, N. K., \& Putra, I. M. P. D. (2015). Pengaruh rasio-rasio keuangan dan ukuran perusahaan pada return saham. E-Jurnal Akuntansi Universitas Udayana, 13(2), 582-598.

Setia, M. O. (2018). Pengembangan Media Pembelajaran Dengan Menggunakan Adobe Flash CS 6 Pada Materi Hukum Newton Tentang Gerak dan Penerapannya. Edufisika: Jurnal Pendidikan Fisika, 3(01), 55-67.

Suharyanto, A. (2015). Pendidikan dan Proses Pembudayaan dalam Keluarga. JUPIIS: Jurnal Pendidikan Ilmu-Ilmu Sosial, 7(2), 162-165.

Suprihatin, S. (2015). Upaya guru dalam meningkatkan motivasi belajar siswa. Jurnal Pendidikan Ekonomi UM Metro, 3(1), 73-82.

Wasty Soemanto. (2003). Psikologi Pendidikan. Malang: Rineka Cipta. 